\title{
The factor structure of major depressive symptoms in a sample of Chinese earthquake survivors
}

Yajie Bi ${ }^{1,2}$, Li Wang ${ }^{1,2^{*}}$, Chengqi Cao ${ }^{1,3}$, Ruojiao Fang ${ }^{1,2}$, Gen Li ${ }^{1,2}$, Ping Liu4 ${ }^{4}$, Shu Luo ${ }^{4}$, Haibo Yang ${ }^{5}$ and Brian J. Hall ${ }^{6}$

\begin{abstract}
Background: Experiencing natural disasters is associated with common mental disorders including major depressive disorder (MDD). However, the latent structure of MDD is widely debated, and few studies tested the MDD factor structure in Chinese natural disaster survivors. Therefore, the aim of the current study was to evaluate the factorial validity of the Patient Health Questionnaire-9 (PHQ-9) for DSM-5 major depressive disorder (MDD) symptoms in Chinese earthquake survivors.

Method: Participants were 1058 Chinese earthquake survivors. Self-reported measures included the PHQ-9 and the Short-Form Health Survey (SF-36). Confirmatory factor analysis (CFA) and structural equation modelling (SEM) was used to examine the latent structure of MDD and the associations between latent factors of MDD and different domains of health-related quality of life (HRQoL), respectively.

Results: In the current sample, the model consisted of somatic and cognitive/affective (non-somatic) factors demonstrated significantly better fit than the other competing MDD models $\left(X^{2}=173.89, d f=26, C F I=0.986, T L I=\right.$ 0.981, RMSEA $=0.073, \mathrm{BIC}=18,091.13$ ). Further SEM analyses indicated that the non-somatic factor was significantly related to both physical $(\beta=-0.362, p<.01)$ and psychosocial HRQOL $(\beta=-0.773, p<.01)$, while the somatic factor was a uniquely predictor of physical HRQOL $(\beta=-0.336, p<.01)$. Furthermore, we found the somatic factor partially mediated the relationship between the cognitive/affective factor and physical HRQoL (all ps $<.05$ ).

Conclusions: The MDD symptoms was best captured by a two-factor model comprised of somatic and cognitive/ affective factors in Chinese natural disaster survivors. The two MDD factors were differentially associated with physical and psychosocial HRQOL, and the cognitive/affective factor associated physical HRQoL partially through the somatic factor. The current findings increase our understanding of latent structure of MDD symptoms, and carry implications for assessment and intervention of post-disaster mental health problems.
\end{abstract}

Keywords: Major depressive disorders, Confirmatory factor analysis, Health-related quality of life, Chinese, Disaster

\footnotetext{
*Correspondence: wangli1@psych.ac.cn

${ }^{1}$ Laboratory for Traumatic Stress Studies, CAS Key Laboratory of Mental

Health, Institute of Psychology, Chinese Academy of Sciences, 16 Lincui Road, Beijing 100101, China

${ }^{2}$ Department of Psychology, University of Chinese Academy of Sciences, Beijing, China

Full list of author information is available at the end of the article
}

(c) The Author(s). 2021 Open Access This article is licensed under a Creative Commons Attribution 4.0 International License, which permits use, sharing, adaptation, distribution and reproduction in any medium or format, as long as you give appropriate credit to the original author(s) and the source, provide a link to the Creative Commons licence, and indicate if changes were made. The images or other third party material in this article are included in the article's Creative Commons licence, unless indicated otherwise in a credit line to the material. If material is not included in the article's Creative Commons licence and your intended use is not permitted by statutory regulation or exceeds the permitted use, you will need to obtain permission directly from the copyright holder. To view a copy of this licence, visit http://creativecommons.org/licenses/by/4.0/ The Creative Commons Public Domain Dedication waiver (http://creativecommons.org/publicdomain/zero/1.0/) applies to the data made available in this article, unless otherwise stated in a credit line to the data. 


\section{Background}

Due to urbanization, environmental degradation, climate change and other factors, the frequency of natural disasters has increased dramatically in recent years [1]. Natural disasters not only cause economic loss, injuries and deaths [2], but also cause severe psychological distress and psychiatric disorders [3]. Major depressive disorder (MDD) is one of the most common psychiatric disorders in natural disaster-exposed populations [4], and MDD symptoms increase with time among natural disasterexposed individuals [5]. Compared to the prevalence of MDD in general population of $4.7 \%$ [6], natural disasterexposed populations range from 10.0-17.6\% [7-10]. Therefore, it is important to develop accurate assessment that guides effective prevention and intervention for MDD after natural disaster. Exploring the factor structure of MDD symptoms could not only benefit our understanding of psychopathological and biological mechanisms, but is also important for the development of more sophisticated clinical assessment and effective treatment programs for this disorder. The PHQ-9 is a self-report questionnaire and maps onto the criteria of MDD in DSM-5 [11]. The reliability and validity of PHQ-9 have been evaluated in numerous populations globally $[12,13]$. The PHQ-9 is one of the most effective and commonly used instrument for measuring depression [14], however, the structure of MDD measured by PHQ-9 is debated.

Several alternative models of MDD symptoms has been proposed and validated in previous studies [13, 15-17] (see Table 1). Model 1 is the unidimensional model based on PCA/CFA studies of primary care patients $[18,19]$ and spinal cord injury patients [20]. A number of studies in various samples (e.g., Chinese adults and adolescents, Mexican women, American college students) have found robust evidence for the unidimensional model that underlies the PHQ-9 [13, 21-23], and many of them excluded two-factor models for the high correlation between MDD factors [22-24]. Other competitive models are similar and comprised of 2 factors: a somatic factor and a cognitive/ affective (non-somatic) factor. Krause et al. (2008, 2010) measured MDD of spinal cord injury patients at an average of 50 days after injury, and proposed the model $2 \mathrm{a}$ in CFA studies $[15,25]$. This finding was confirmed by a longitudinal study of palliative care patients [26]. Model 2b was based on a CFA study of coronary heart disease patients [16]. Model 2c was proposed in EFA and CFA studies among spinal cord injury patients [25, 27], and was confirmed by the CFA studies in soldiers [17], primary care patients in Germany [28], Filipino and Indonesian female domestic workers in China [29, 30], mental health patients [31] and university students in Colombia [22]. Model 2d was first described in the sample of spinal cord injury patients at 30 months after injury [25]. Notably, Model 2c has been confirmed in more studies than the other competing models [17, 28-30], and this may be attributed to type of populations, demographics, health condition, and history of trauma exposure [29].

Many studies have explored the factor structure of MDD, while few of them clarified the different functional roles of MDD symptom clusters. Simms (2002) suggested that external measures of psychopathology should be examined to clarify this issue [33]. As highlighted by several studies, MDD is tightly associated to poor HRQoL [34], and QoL is an important consideration of treatment-outcome assessment in MDD patients [35]. Previous studies suggested that somatic symptoms (i.e., sleep disturbance, fatigue and appetite change) were uniquely associated with reduced physical health [36, 37]. Furthermore, some non-somatic symptoms such as feeling worthless and suicidal ideas might be related closely to poor psychosocial functioning [38, 39], and could reduce physical health [40]. Therefore, the discriminant validity of the best fitting model can be examined by estimating the correlations between factors of MDD and external measures of HRQoL.

Table 1 Item mapping for confirmatory factor analysis

\begin{tabular}{|c|c|c|c|c|c|}
\hline PHQ-9 Items & Model 1 & Model 2a & Model 2b & Model 2c & Model 2d \\
\hline Anhedonia & Depression & Non-somatic & Non-somatic & Non-somatic & Somatic \\
\hline Depressed mood & Depression & Non-somatic & Non-somatic & Non-somatic & Non-somatic \\
\hline Sleep difficulties & Depression & Somatic & Somatic & Somatic & Somatic \\
\hline Fatigue & Depression & Somatic & Somatic & Somatic & Somatic \\
\hline Appetite changed & Depression & Somatic & Somatic & Somatic & Somatic \\
\hline Feeling of worthless & Depression & Non-somatic & Non-somatic & Non-somatic & Non-somatic \\
\hline Concentration difficulties & Depression & Non-somatic & Non-somatic & Somatic & Somatic \\
\hline Psychomotor agitations/retardation & Depression & Non-somatic & Somatic & Somatic & Somatic \\
\hline Thoughts of death & Depression & Non-somatic & Non-somatic & Non-somatic & Non-somatic \\
\hline
\end{tabular}

Model 1 posits that a single one-dimension factor underlies the PHQ-9; Model 2a: Krause et al. [15], Krause et al. [25], Chilcot et al. [26]; Model 2b: de jonge et al. [16]; Model 2c: Krause et al. [25], Richardson \& Richards, [27], Elhai et al. [17], Petersen et al. [28], Mordeno et al. [29], Guo et al. [31], Miranda \& Scoppetta [32]. Model 2d: Krause et al. [25] 
Previous studies revealed that people who suffer from MDD often had physical problems [41, 42], and some psychotherapies (e.g., cognitive therapy) have positive effects on the physical problems of MDD patients [43]. Therefore, investigations are needed that document the association between MDD symptoms and physical HRQoL. However, few studies discussed this issue. Nonsomatic and somatic depression factors might be related to physical HRQoL. Within traditional Chinese culture, people are reluctant to express their emotions and psychological distress. They tend to attribute psychological problems to physical or external origins [44]. Therefore, cognitive/affective symptoms of MDD might be expressed through somatic symptoms in Chinese samples, which may in turn affect physical HRQoL.

The first aim of this study was to find the best fitting latent structural model of MDD; our second aim was to evaluate whether the somatic factor mediates the relationship between non-somatic factor and physical HRQoL. According to prior studies, our hypotheses were as follows: (1) the model comprised of a somatic factor and a cognitive/affective factor would provide a superior data fit over competing models; (2) the non-somatic factor would be associated with psychosocial health and physical health. Relatedly, we expected the somatic factor would correlate with physical health only; and, (3) the non-somatic factor would affect physical HRQoL through the somatic factor. Many previous study samples were restricted to medical patients (e.g. patients with spinal cord injury, coronary heart disease patients), which might increase the endorsement rates of the MDD somatic symptoms and therefore might affect the factor structure of $\operatorname{MDD}[15,16,25,27]$. Our study is the first one to use disaster-exposed sample, which could examine the generalizability of previous results and extend current knowledge on MDD symptom structure.

\section{Methods}

\section{Procedure and participants}

On May 12, 2008, a destructive earthquake measuring 8.0 on the Richter scale occurred in Sichuan Province. For the purposes of accessing disaster-related mental health problems, the sample was collected from 5 rebuilt communities of Hanwang town, Mianzhu City. Approximately 5000 people living in this town were killed in the earthquake. This survey was conducted in July, 2017. The procedures were as follows: (1) Selecting one family member randomly in each household as participants; (2) making sure that all participants were aged from 16 to 65 and experienced the 2008 earthquake; (3) excluding individuals with mental retardation or a major psychiatry history. This survey was conducted by professional clinical psychologists, psychology students. Before the participants completed questionnaires, the aim of the study was clearly explained. All participants have signed an informed consent. This study protocol was reviewed and approved by the Institutional Review Board of the Institute of Psychology, Chinese Academy of Sciences. A total of 1072 people participated in this study. People with missing data ( $>20 \%$ items) were excluded $(n=14)$, leaving an effective sample of 1058.

\section{Measures}

MDD symptoms were accessed using the PHQ-9, which is a nine-item instrument from the Primary Care Evaluation of Mental Disorders (PRIME-MD). PHQ-9 is a brief, easily administered self-report questionnaire designed to capture MDD symptoms. Each item is rated on a 4-point scale using anchors ranging from 0 (not at all) to 3 (extremely), reflecting the extent which symptom bothers a participant in the past 2 weeks. The reliability and validity of the PHQ-9 have been well-documented in a previous study [14]. The PHQ-9 has been translated to more than 80 languages and widely used worldwide, and the Chinese version of PHQ-9 has been reported to have good psychometric properties [12]. Cronbach's $\alpha$ for PHQ-9 was 0.89 in the current sample.

The Short-Form Health Survey (SF-36) was used to assess health-related quality of life. There are 8 subscales in this instrument, 4 reflect Physical HRQoL (consisting of physical functioning, role-physical, bodily pain and general health), and 4 reflect Psychological HRQoL (consisting of role-emotional, social functioning, mental health and fatigue). Scores of all subscales range from 0 to 100 , with higher scores indicating a better HRQoL. The Chinese version of SF-36 has been proven to have good reliability and validity, and widely used in Chinese populations [45]. Wang (2014) identified that the PHQ-9 total score correlated negatively with each subscale's score of the SF-36 [12]. We select scales of SF-36 because their content can explicitly address psychosocial functioning. Mental health and Fatigue subscales were excluded for the observation of spurious relationship with the MDD measures.

\section{Statistical analysis}

All descriptive analyses were conducted using the SPSS 20.0 for Windows. Of the 1058 participants, 36 were missing one PHQ-9 item, 284 were missing one to three SF-36 items and 6 were missing four to six SF-36 items. Missing values on the PHQ-9 were handled with full information maximum likelihood (ML) procedures. According to the scoring procedures of the SF-36, the missing values on the SF-36 were estimated with the average score of the same subscales.

To evaluate the best-fitting factor model, five alternative CFA models (see Table 1) previously identified were tested in the current study. According to previous 
studies, items should be treated as categorical variables when measures contain fewer than five options, and Weighted Least Squares Estimation with a mean and variance adjusted (WLSMV) should also be used [46]. Therefore, all measurement models were evaluated using CFA and WLSMV in Mplus 7.0. Three conventional indices (CFI, TLI and RMSEA) were used to evaluate the internal fit of the models. For these indices, an excellent fit is indicated by CFI and TLI of 0.95 and above, RMSEA of 0.06 or less, and an acceptable fit is indicated by CFI and TLI of 0.90 and above, RMSEA of 0.08 or less [47]. Chisquare difference tests were conducted to compare nested models using the DIFFTEST function in Mplus. The Bayesian information criterion (BIC) were used to compare non-nested models. A BIC difference of 6-10 provides strong support and a difference greater than 10 indicates very strong support for the model with the lower $\mathrm{BIC}$ value [48]. However, the BIC can only be generated by ML, therefore, we use maximum likelihood estimation with robust standard (MLR) to compute this index.

We subsequently incorporated two structural equation models to evaluate the correlations between each MDD factor and each component of HRQoL. In the first model, physical health was treated as a latent factor measured by the physical functioning, role-physical, bodily pain, and general health subscales of SF-36 subscales (for estimation of latent variables could reduce the measurement error compared with summing sub-scales' scores), and was set as the dependent latent variable. In the second model, psychosocial quality of life was treated as a latent factor measured by the role-emotional and social functioning, and was set as the dependent latent variable. MDD factors of the best fitting model and covariates (age, gender, educational level and marital status) were simultaneously included in the equation as predictors in all models. SEM was used to test all models, and regression coefficients were calculated to examine the different correlations between each MDD factor with physical and psychosocial HRQoL.

A SEM model was built to examine the mediator role of MDD's somatic factor between MDD's non-somatic factor and physical HRQoL, standard errors of the mediating parameter were simultaneously estimated in the SEM model with bootstrap procedure (1000 times). Direct effects in this study include the relationship between MDD's somatic and cognitive/affective factors, between MDD's somatic factors and physical health, and between MDD's non-somatic factors and physical health. Indirect effects included the effect of MDD's cognitive/affective factor on physical health through MDD's somatic factor.

\section{Results}

\section{Descriptive statistics}

In the current sample, 347 (32.7\%) men and 711 (67.3\%) women with a mean age of 51.1 (range: $16-65, S D=$
10.0), 911 (86.2\%) were married, and 146 (13.8\%) were unmarried (consisting of never married, divorced, widowed). 1042 (98.6\%) were Han people, and 5 (0.4\%) were members of other ethnic groups (including Zang, Qiang and Hui). 732 (69.2\%) did not complete high school, 240 (22.7\%) completed high school, and 85 (8.0\%) completed college.

Descriptive statistics for the PHQ-9 and SF-36 total scores were estimated at first. Mean PHQ-9 score was 6.2 (range: $0-27, S D=5.0)$, and $236(22.2 \%)$ participants were diagnosed with possible MDD (based on the diagnostic algorithm of using a cutoff score of 10 or higher).

Mean scores on the SF-36 subscales were as follows: "Physical Functioning" was $79.2(S D=24.2$, range: 0 100), "Role limitations due to physical health" was 64.4 $(S D=41.0$, range: $0-100)$, "Bodily Pain" was 76.4 $(S D=$ 22.3, range: $0-100)$, "General Health" was $60.7(S D=$ 21.2, range: $0-100)$, "Social Functioning" was $79.6(S D=$ 21.4, range: $0-100$ ), and the "Role limitations due to emotional problems" was $60.3(S D=41.6$, range: $0-100)$.

\section{Comparison of competitive models}

Table 2 presents internal fit indices of alternative models. Only Model 2a yielded acceptable fit, while other models were rejected due to large RMSEA values. Table 3 displays results of Chi-square difference tests for nested models, only Model 2a was superior to model 1 $\left(\Delta \chi^{2}(1)=45.653, p<0.001\right)$. In terms of comparisons of non-nested models, the BIC value for model $2 \mathrm{a}$ was lower than the other models, and all $\triangle \mathrm{BIC}$ were lower than 6 except the $\triangle \mathrm{BIC}$ between Model 2a and other models. For these reasons, the Model $2 \mathrm{a}$ was the best fitting model (see Tables 2 and 3). The standardized factor loadings and factor intercorrelations of Model 2a were summarized in Fig. 1.

\section{Correlations between PHQ-9 factors and HRQoL components}

The models examining correlations between MDD factors and HRQoL demonstrated adequate fit. Fit statistics were $\chi^{2}(110, N=1058)=218.08, \mathrm{CFI}=0.99$, TLI $=0.99$, RMSEA $=0.03$ (90\% CI: 0.03-0.04) for the model with physical HRQoL as dependent variable, and $\chi^{2}(81, N=$ $1058)=243.98, \quad$ CFI $=0.99, \quad$ TLI $=0.98, \quad$ RMSEA $=0.04$ (90\% CI: $0.04 \sim 0.05)$ for the model with psychosocial HRQoL as a dependent variable. Table 4 summarizes the associations between the two MDD factors and physical and psychosocial HRQoL. After controlling other variables, the somatic factor significantly predicted the physical HRQoL $(\beta=-0.336, p<.01)$, and the cognitive/affective factor was a significant predictor for both physical HRQoL $(\beta=-0.362, p<.01)$ and psychosocial HRQoL $(\beta=-0.773, p<.01)$. 
Table 2 Model goodness of fit indices

\begin{tabular}{llllllll}
\hline Model & $\boldsymbol{X}^{2}$ & $\boldsymbol{d f}$ & CFI & TLI & RMSEA & RMSEA 90\% CI & BIC \\
\hline Model 1 & 239.38 & 27 & 0.980 & 0.974 & 0.086 & $0.076-0.096$ & $18,129.67$ \\
Model 2a & 173.89 & 26 & 0.986 & 0.981 & 0.073 & $0.063-0.084$ & $18,091.13$ \\
Model 2b & 233.96 & 26 & 0.981 & 0.974 & 0.087 & $0.077-0.097$ & $18,134.56$ \\
Model 2c & 235.07 & 26 & 0.981 & 0.973 & 0.087 & $0.077-0.098$ & $18,135.16$ \\
Model 2d & 237.65 & 26 & 0.981 & 0.973 & 0.088 & $0.077-0.098$ & $18,133.81$ \\
\hline
\end{tabular}

$N=1058$. CFI comparative fit index, TLI Tucker-Lewis index, RMSEA root mean square error of approximation, $C I$ confidence interval, BIC Bayesian information criterion

\section{The mediating effect of the somatic factor}

The indirect effect of the non-somatic factor on physical HRQoL was significant $(\beta=-0.296, p<.05)$ (see Fig. 2). Results indicated significant effects of the cognitive/ affective factor on the somatic factor $\left(\beta_{1}=0.922, S E=\right.$ 0.016, $p<.05)$ and the somatic factor on physical HRQoL $\left(\beta_{2}=-0.321, S E=0.153, p<.05\right)$. The path from cognitive/affective factor to physical HRQoL was also significant $\left(\beta_{3}=-0.383, S E=0.149, p<.05\right)$. After 1000 bootstrapped tests, the somatic factor still significantly mediated the relationship (95\% CI of $\beta_{1}$ : 0.894 0.957; 95\% CI of $\beta_{2}:-0.645 \sim-0.061 ; 95 \%$ CI of $\beta_{3}:-0.629 \sim$ -0.082 ; $95 \%$ CI of indirect effect: $-0.581 \sim-0.057$ ).

\section{Discussion}

The current study investigated the factor structure of MDD symptoms measured by PHQ-9 in a sample of Chinese earthquake survivors, found the two-factor model of MDD symptoms is the best fitting model, and MDD factors had different associations with physical and psychosocial HRQoL. Since Krause (2008) proposed that MDD symptoms could be best captured by somatic and cognitive/affective factors, many studies supported two-factor MDD models in samples with somatic conditions (e.g. patients with spinal cord injury, coronary heart disease patients) $[15,16,25,27]$. However, using samples of patients with somatic conditions might increase endorsement rates of MDD somatic symptoms, and thus might influence the factor structure of MDD. Our findings were consistent with results of previous studies used medical patients $[15,16,25,27,28]$ and used other samples $[17,29,30]$, and support separating the MDD into a somatic factor and cognitive/affective factor. In the current sample, the correlation between

Table 3 Chi-square difference test for comparing nest models

\begin{tabular}{lll}
\hline Models & ${ }_{\boldsymbol{X}} \boldsymbol{X}^{\mathbf{(}(\boldsymbol{f})}$ & $\boldsymbol{p}$ \\
\hline Model 1 vs Model 2a & $45.65(1)$ & $<0.001$ \\
Model 1 vs Model 2b & $6.52(1)$ & 0.011 \\
Model 1 vs Model 2c & $5.36(1)$ & 0.021 \\
Model 1 vs Model 2d & $2.91(1)$ & 0.088 \\
\hline
\end{tabular}

$N=1058$ two MDD factors was 0.92 , this might be criticized for lacking of discriminant validity. However, high correlation between factors cannot be enough to prove that the model lacks discriminant validity. First, the current study and many previous studies have found that the two-factor MDD model had significantly better fitting statistics than the one-factor MDD model [17, 28-30, 49]. In addition, the results yielded from bootstrap analysis showed that the $95 \% \mathrm{CI}$ of correlation coefficient between somatic and non-somatic factors did not include 1 (0.890-0.953), further justified separating these two factors. These findings indicated that MDD symptoms could be captured by somatic and cognitive/affective factors. Second, Mordeno et al. (2018) have found that somatic symptoms (measured by PHQ-15) were more closely related to the somatic factor than the cognitive/ affective factor of MDD [29], and the present study also found the physical and psychosocial HRQoL had different associations with the somatic factor and the cognitive/affective factor of MDD. These findings provided evidence for the external validity of the distinction between the MDD somatic and non-somatic factors. Third, the two-factor model could be better interpreted as different symptomatic representation and subtypes of MDD than the unidimensional model [50, 51]. A number of empirical studies used machine learning, genetic, and biological approaches to yield strong evidence in favor of MDD consisting of somatic and affective/cognitive factors, rather than one "depression" factor [51-53]. It is interesting that the best fitting model in this study contradicted the results of Elhai et al. (2012), Petersen et al. (2015) and Mordeno et al. (2018). The concentrating difficulties and psychomotor agitation/retardation loaded on the cognitive/affective factor in the current study. Papakostas (2013) reported that concentration difficulties and the psychomotor agitation/retardation symptoms reflected deficits in cognitive functions, and subsequent research using the Research Domain Criteria (RDoC) framework confirmed that these two symptoms should be classified in cognitive and sensorimotor systems [53, 54]. Moreover, two recent CFA studies have found similar conclusions in adults with autism and in the general US population $[55,56]$. 


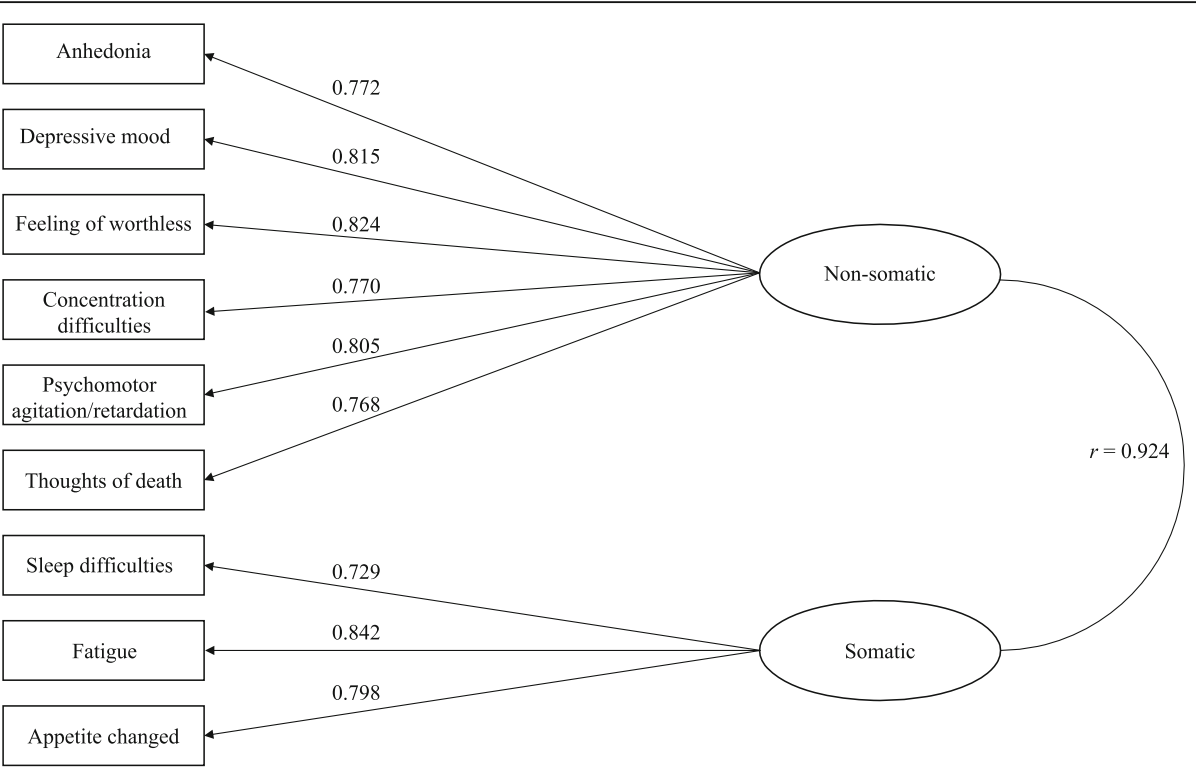

Fig. 1 The two-factor model of MDD symptoms assessed by PHQ-9. Note. $N=1058$; All correlations are statistically significant $(p<0.01)$

To further verify the distinctiveness of the two MDD's factors, the current study used HRQoL as an external measure, and found that HRQoL displayed specific associations with two factors of MDD. Previous studies also had similar findings. The results of Mordeno et al., (2018)'s study revealed that somatic symptoms (measured by PHQ-15) were more related to the somatic factor than cognitive/affective factor [29]. Elhai et al. (2011) also found that in Canadian military veterans measured by Center for Epidemiologic Studies-Depression Scale (CES-D), depression's somatic items had higher relationship with some factors of posttraumatic stress disorder (PTSD) than non-somatic items [57]. Finally, another study demonstrated that the Australian and UK samples measured by the Gotland Scale of Male Depression (GSMD) were best represented by a two-factor (affective and somatic) MDD model [58]. The results supported our hypotheses, and illustrated that the distinct factors of MDD might play different functional roles in the HRQoL of people with depression and provided further robust support for the two-factor MDD model.
Furthermore, based on previous theoretical evidence, we assessed the mediating role of somatic factor referencing the relationship between the non-somatic factor and physical HRQoL. Results indicated that the nonsomatic factor of MDD probably affects the physical HRQoL via the MDD somatic factor in the present sample. This may have a cultural explanation. For example, expressing psychological distress is considered a dilemma in Chinese culture. People who experience psychological problems tend to attribute these problems to physical or external origins $[44,59]$. This might be the reason that psychological problems were often expressed in the form of physical illness in Asian populations. Our findings partially clarified the pattern of MDD's nonsomatic factor influencing the physical HRQoL in the Chinese natural disaster survivors.

Finding of this study has several implications for clinical applications. First, investigation of the factor structure of MDD could help us better understanding different components of MDD symptoms, which could guide clinically useful assessment and intervention for MDD symptoms. Second, findings of our study informed

Table 4 Relationship between MDD factors and health related quality of life

\begin{tabular}{lllll}
\hline Dependent variables & Predictor & $\boldsymbol{r}$ & $\boldsymbol{B}$ & $\boldsymbol{\beta}$ \\
\hline Physical health-related quality of life & Somatic & -0.674 & $-5.637^{*}$ & $-5.687^{*}$ \\
Psychosocial health-related quality of life & Non-somatic & -0.678 & $-0.336^{*}$ \\
& Somatic & -0.691 & 0.795 & $-0.362^{*}$ \\
\hline
\end{tabular}




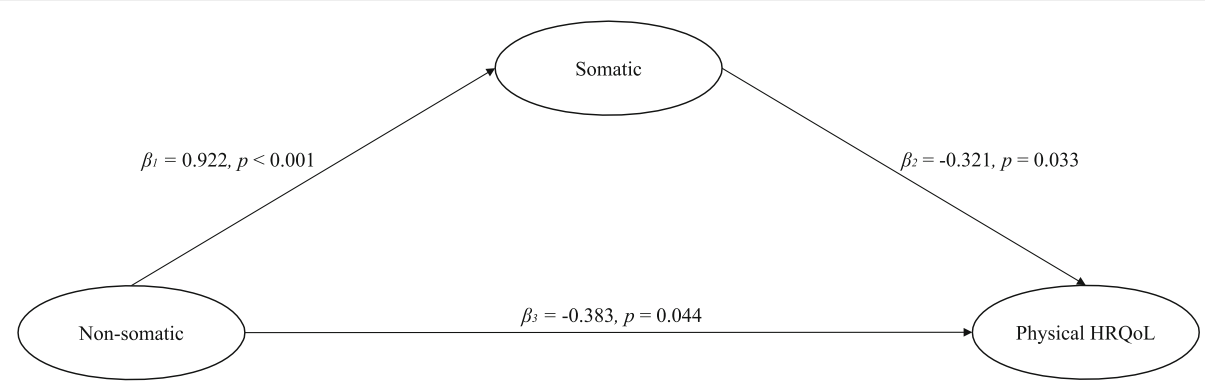

Indirect effect $\left(\beta_{l}=-0.296, p=0.037,95 \%\right.$ CI: $\left.-0.581 \sim-0.057\right)$

Fig. 2 Mediating role of MDD's somatic factor in the relationship between MDD's non-somatic and physical health-related quality of life. Note. $N=1058$. HRQol, health-related quality of life

the different functional roles that distinct factors of MDD played in HRQoL. This would be helpful to structure and establish treatment which aims to improve the HRQoL of people with depression. Third, our findings benefit our understanding of the psychopathological process of MDD symptoms affecting physical HRQoL. Our findings illustrated that for Chinese people with significant somatic symptoms, their psychological problems need also to be recognized.

There are several study limitations that need to be recognized. First, our findings might be limited because we used an earthquake-exposed sample. Thus, samples exposed to other trauma types should be used to further replicate our findings. Second, the limitation of selfreported symptoms has been acknowledged [60]. Therefore, additional replications with samples measured by clinical-administered MDD instruments are warranted. Third, variables which was used to evaluate the MDD model's external validity in this study was limited. The external validity of this MDD model should be evaluated with other types of variables which related to MDD in the future studies. Fourth, the cross-sectional design has certain limitations in explaining causality [61]. This needs further verification by future longitudinal studies.

\section{Conclusion}

Survivors of natural disasters typically have a high MDD prevalence, and accurately assessing MDD symptoms among this population is very important for postdisaster mental health care. The present study found that MDD could be best represented by the two-factor model in Chinese natural disaster survivors, and the MDD factors have different relationships with HRQoL. Our findings could help to better understand the different components of MDD among natural disaster victims, which could guide more sophisticated assessment and intervention for their MDD symptoms. Moreover, findings of the current study are important in contributing to improving HRQoL of natural disaster victims.

\section{Abbreviations}

MDD: Major depressive disorder; PHQ-9: Patient health questionnaire-9; SF36: Short-form health survey; HRQOL: Health-related quality of life; CFA: Confirmatory factor analysis; SEM: Structural equation modelling; CFI: Comparative fit index; TLl: Tucker-Lewis index; RMSEA: Root-mean square error of approximation

\section{Acknowledgments}

The authors appreciate all the staff for their help, and thank the contribution of all participants.

\section{Authors' contributions}

LW designed the current study. PL, SL, RJF, YJB and GL oversaw data collection. YJB supervised data analysis and drafted the manuscript. LW, CQC, $\mathrm{RJF}, \mathrm{GL}, \mathrm{BJH}$ and $\mathrm{HBY}$ read the manuscript and provided critical revision for it. All authors have read and approved the manuscript.

\section{Funding}

This study was partially supported by the External Cooperation Program of Chinese Academy of Sciences (No. 153111KYSB20160036), the National Natural Science Foundation of China (No. 31471004, 31971020), the Key Project of the National Social Science Foundation of China (No. 20ZDA079), the Key Project of Research Base of Humanities and Social Sciences of Ministry of Education (No.16JJD190006), and the Key Research Program of the Chinese Academy of Sciences (No.ZDRW-XH-2019-4). The funders have no involvement with the research.

All of the above-mentioned funding sources had no further role in the study design, in the collection/analysis/interpretation of data and in writing the manuscript.

\section{Availability of data and materials}

The datasets used and/or analyzed in the current study are available from the corresponding author upon reasonable request.

\section{Ethics approval and consent to participate}

The survey protocol was reviewed and approved by the Institutional Review Board of the Institute of Psychology, Chinese Academy of Sciences, and we obtained written informed consent from all participants.

\section{Consent for publication}

Not applicable.

\section{Competing interests}

The authors declare that they have no competing interests.

\section{Author details}

${ }^{1}$ Laboratory for Traumatic Stress Studies, CAS Key Laboratory of Mental Health, Institute of Psychology, Chinese Academy of Sciences, 16 Lincui Road, Beijing 100101, China. 'Department of Psychology, University of Chinese Academy of Sciences, Beijing, China. ${ }^{3}$ Shenzhen Key Laboratory of Affective and Social Cognitive Science, Shenzhen University, Shenzhen, China. ${ }^{4}$ People's Hospital of Deyang City, Deyang, Sichuan, China. ${ }^{5}$ Academy of Psychology and Behavior, Tianjin Normal University, Tianjin, China. ${ }^{6} \mathrm{Global}$ 
and Community Mental Health Research Group, New York University (Shanghai), Pudong, Shanghai, China.

\section{Received: 19 November 2019 Accepted: 30 November 2020 Published online: 28 January 2021}

\section{References}

1. Leaning J, Guha-Sapir D. Natural disasters, armed conflict, and public health N Engl J Med. 2013;369:1836-42 https://doi.org/10.1056/NEJMra1109877.

2. Fang J, Lau CKM, Lu Z, Wu W, Zhu L. Natural disasters, climate change, and their impact on inclusive wealth in G20 countries. Environ Sci Pollut Res Int. 2019;26:1455-63 https://doi.org/10.1007/s11356-018-3634-2.

3. Beaglehole B, Mulder RT, Frampton CM, Boden JM, Newton-Howes G, Bell CJ. Psychological distress and psychiatric disorder after natural disasters: systematic review and meta-analysis. Br J Psychiatry. 2018;213:716-22 https://doi.org/10.1192/bjp.2018.210

4. North CS, Kawasaki A, Spitznagel EL, Hong BA. The course of PTSD, major depression, substance abuse, and somatization after a natural disaster. J Nerv Ment Dis. 2004;192:823-9 https://doi.org/10.1097/01.nmd.0000146911. 52616.22 .

5. Pennington ML, Carpenter TP, Synett SJ, Torres VA, Teague J, Morissette SB, et al. The influence of exposure to natural disasters on depression and PTSD symptoms among firefighters. Prehosp Disaster Med. 2018;33:102-8 https:// doi.org/10.1017/S1049023X17007026.

6. Ferrari AJ, Somerville AJ, Baxter AJ, Norman R, Patten SB, Vos T, Whiteford HA. Global variation in the prevalence and incidence of major depressive disorder: a systematic review of the epidemiological literature. Psychol Med. 2013:43:471-81 https://doi.org/10.1017/S0033291712001511.

7. Aziz S, Aslam N. Psychiatric morbidity and work and social adjustment among earthquake survivors extricated from under the rubble. Indian J Psychol Med. 2012:34:346-9 https://doi.org/10.4103/0253-7176.108215.

8. Hussain A, Weisaeth L, Heir T. Psychiatric disorders and functional impairment among disaster victims after exposure to a natural disaster: a population based study. J Affect Disord. 2011;128:135-41 https://doi.org/10. 1016/j.jad.2010.06.018.

9. Kar N, Bastia BK. Post-traumatic stress disorder, depression and generalised anxiety disorder in adolescents after a natural disaster: a study of comorbidity. Clin Pract Epidemiol Ment Health. 2006;2:17 https://doi.org/10. 1186/1745-0179-2-17.

10. Kristensen P, Weisaeth L, Hussain A, Heir T. Prevalence of psychiatric disorders and functional impairment after loss of a family member: a longitudinal study after the 2004 tsunami. Depress Anxiety. 2015;32:49-56 https://doi.org/10.1002/da.22269.

11. American Psychiatric Association, publisher, American Psychiatric Association. DSM-5 Task Force. Diagnostic and statistical manual of mental disorders: DSM-5. Arlington: American Psychiatric Association; 2013.

12. Wang W, Bian Q, Zhao Y, Li X, Wang W, Du J, et al. Reliability and validity of the Chinese version of the patient health questionnaire (PHQ-9) in the general population. Gen Hosp Psychiatry. 2014;36:539-44 https://doi.org/10. 1016/j.genhosppsych.2014.05.021

13. Tsai F-J, Huang Y-H, Liu H-C, Huang K-Y, Huang Y-H, Liu S-I. Patient health questionnaire for school-based depression screening among Chinese adolescents. Pediatrics. 2014;133:e402-9 https://doi.org/10.1542/peds.20130204.

14. Kroenke K, Wu J, Yu Z, Bair MJ, Kean J, Stump T, Monahan PO. Patient health questionnaire anxiety and depression scale: initial validation in three clinical trials. Psychosom Med. 2016;78:716-27 https://doi.org/10.1097/PSY. 0000000000000322.

15. Krause JS, Bombardier C, Carter RE. Assessment of depressive symptoms during inpatient rehabilitation for spinal cord injury: is there an underlying somatic factor when using the PHQ? Rehabil Psychol. 2008;53:513-20 https://doi.org/10.1037/a0013354.

16. de Jonge $\mathrm{P}$, Mangano D, Whooley MA. Differential association of cognitive and somatic depressive symptoms with heart rate variability in patients with stable coronary heart disease: findings from the heart and soul study Psychosom Med. 2007;69:735-9 https://doi.org/10.1097/PSY. Ob013e31815743ca.

17. Elhai JD, Contractor AA, Tamburrino M, Fine TH, Prescott MR, Shirley E, et al. The factor structure of major depression symptoms: a test of four competing models using the patient health Questionnaire-9. Psychiatry Res. 2012;199:169-73 https://doi.org/10.1016/j.psychres.2012.05.018.
18. Huang FY, Chung H, Kroenke K, Delucchi KL, Spitzer RL. Using the Patient Health Questionnaire-9 to measure depression among racially and ethnically diverse primary care patients. J Gen Intern Med. 2006;21:547-52 https://doi.org/10.1111/j.1525-1497.2006.00409.x.

19. Cameron IM, Crawford JR, Lawton K, Reid IC. Psychometric comparison of PHQ-9 and HADS for measuring depression severity in primary care. $\mathrm{Br}$ Gen Pract. 2008;58:32-6 https://doi.org/10.3399/bjgp08X263794.

20. Kalpakjian CZ, Toussaint LL, Albright KJ, Bombardier CH, Krause JK, Tate DG. Patient Health Questionnaire-9 in Spinal Cord Injury: An Examination of Factor Structure as Related to Gender. J Spinal Cord Med. 2009;32:147-56.

21. Yu X, Tam WWS, Wong PTK, Lam TH, Stewart SM. The Patient Health Questionnaire-9 for measuring depressive symptoms among the general population in Hong Kong. Compr Psychiatry. 2012;53:95-102 https://doi.org/ 10.1016/j.comppsych.2010.11.002

22. Familiar I, Ortiz-Panozo E, Hall B, Vieitez I, Romieu I, Lopez-Ridaura R, Lajous M. Factor structure of the Spanish version of the Patient Health Questionnaire-9 in Mexican women. Int J Methods Psychiatr Res. 2015:24: 74-82 https://doi.org/10.1002/mpr.1461.

23. Keum BT, Miller MJ, Inkelas KK. Testing the factor structure and measurement invariance of the PHQ-9 across racially diverse U.S. college students. Psychol Assess. 2018;30:1096-106 https://doi.org/10.1037/ pas0000550.

24. González-Blanch C, Medrano LA, Muñoz-Navarro R, Ruíz-Rodríguez P, Moriana JA, Limonero JT, et al. Factor structure and measurement invariance across various demographic groups and over time for the PHQ-9 in primary care patients in Spain. PLoS One. 2018;13:e0193356 https://doi. org/10.1371/journal.pone.0193356.

25. Krause JS, Reed KS, MCArdle JJ. Factor structure and predictive validity of somatic and nonsomatic symptoms from the patient health questionnaire9: a longitudinal study after spinal cord injury. Arch Phys Med Rehabil. 2010; 91:1218-24 https://doi.org/10.1016/j.apmr.2010.04.015.

26. Chilcot J, Rayner L, Lee W, Price A, Goodwin L, Monroe B, et al. The factor structure of the PHQ-9 in palliative care. J Psychosom Res. 2013;75:60-4 https://doi.org/10.1016/j.jpsychores.2012.12.012.

27. Richardson EJ, Richards JS. Factor structure of the PHQ-9 screen for depression across time since injury among persons with spinal cord injury. Rehabil Psychol. 2008;53:243-9 https://doi.org/10.1037/0090-5550.53.2.243.

28. Petersen JJ, Paulitsch MA, Hartig J, Mergenthal K, Gerlach FM, Gensichen J. Factor structure and measurement invariance of the Patient Health Questionnaire-9 for female and male primary care patients with major depression in Germany. J Affect Disord. 2015;170:138-42 https://doi.org/10. 1016/j.jad.2014.08.053

29. Mordeno IG, Carpio JGE, Mendoza NB, Hall BJ. The latent structure of major depressive symptoms and its relationship with somatic disorder symptoms among Filipino female domestic workers in China. Psychiatry Res. 2018;270: 587-94 https://doi.org/10.1016/j.psychres.2018.10.029.

30. Hall BJ, Patel A, Lao L, Liem A, Mayawati EH, Tjipto S. Structural validation of The Patient Health Questionnaire-9 (PHQ-9) among Filipina and Indonesian female migrant domestic workers in Macao: STRUCTURAL VALIDATION OF PHQ-9. Psychiatry Res. 2020:113575 https://doi.org/10.1016/j.psychres.2020. 113575.

31. Guo B, Kaylor-Hughes C, Garland A, Nixon N, Sweeney T, Simpson S, et al. Factor structure and longitudinal measurement invariance of $\mathrm{PHQ}-9$ for specialist mental health care patients with persistent major depressive disorder: Exploratory Structural Equation Modelling. J Affect Disord. 2017; 219:1-8 https://doi.org/10.1016/j.jad.2017.05.020.

32. Miranda CAC, Scoppetta O. Factorial structure of the Patient Health Questionnaire-9 as a depression screening instrument for university students in Cartagena, Colombia. Psychiatry Res. 2018;269:425-9 https://doi. org/10.1016/j.psychres.2018.08.071

33. Simms LJ, Watson D, Doebbeling BN. Confirmatory factor analyses of posttraumatic stress symptoms in deployed and nondeployed veterans of the Gulf War. J Abnorm Psychol. 2002;111:637-47 https://doi.org/10.1037// $0021-843 \times 111.4637$

34. Daly EJ, Trivedi MH, Wisniewski SR, Nierenberg AA, Gaynes BN, Warden D, et al. Health-related quality of life in depression: A STAR*D report. Ann Clin Psychiatry. 2010;22:43-55.

35. Ishak WW, Ha K, Kapitanski N, Bagot K, Fathy H, Swanson B, et al. The impact of psychotherapy, pharmacotherapy, and their combination on quality of life in depression. Harv Rev Psychiatry. 2011;19:277-89 https://doi. org/10.3109/10673229.2011.630828 
36. Hofer F, Koinig KA, Nagl L, Borjan B, Stauder R. Fatigue at baseline is associated with geriatric impairments and represents an adverse prognostic factor in older patients with a hematological malignancy. Ann Hematol. 2018:97:2235-43 https://doi.org/10.1007/s00277-018-3420-8.

37. Koutoukidis DA, Knobf MT, Lanceley A. Obesity, Diet, Physical Activity, and Health-Related Quality of Life in Endometrial Cancer Survivors. Nutr Clin Care. 2015;73:399-408

38. Jatoi I, Zhu K, Shah M, Lawrence W. Psychological distress in U.S. Women who have experienced false-positive mammograms. Breast Cancer Res Treat. 2006;100:191-200.

39. Xie P, Wu K, Zheng Y, Guo Y, Yang Y, He J, et al. Prevalence of childhood trauma and correlations between childhood trauma, suicidal ideation, and social support in patients with depression, bipolar disorder, and schizophrenia in southern China. J Affect Disord. 2018;228:41-8 https://doi. org/10.1016/j.jad.2017.11.011.

40. Kendall-Tackett K. Psychological trauma and physical health: A psychoneuroimmunology approach to etiology of negative health effects and possible interventions. Psychol Trauma Theory Res Pract Policy. 2009;1: 35-48 https://doi.org/10.1037/a0015128.

41. Adan A, Marquez-Arrico JE, Gilchrist G. Comparison of health-related quality of life among men with different co-existing severe mental disorders in treatment for substance use. Health Qual Life Outcomes. 2017;15:209 https://doi.org/10.1186/s12955-017-0781-y.

42. Jim HSL, Small BJ, Minton S, Andrykowski M, Jacobsen PB. History of major depressive disorder prospectively predicts worse quality of life in women with breast cancer. Ann Behav Med. 2012;43:402-8 https://doi.org/10.1007/ s12160-011-9333-6.

43. Jaracz J, Gattner K, Jaracz K, Górna K. Unexplained Painful Physical Symptoms in Patients with Major Depressive Disorder: Prevalence, Pathophysiology and Management. CNS Drugs. 2016;30:293-304 https://doi. org/10.1007/s40263-016-0328-5.

44. Wang X, Gao L, Shinfuku N, Zhang H, Zhao C, Shen Y. Longitudinal Study of Earthquake-Related PTSD in a Randomly Selected Community Sample in North China. Am J Psychiatry. 2000;157:1260-6.

45. Lam CL, Gandek B, Ren XS, Chan MS. Tests of scaling assumptions and construct validity of the Chinese (HK) version of the SF-36 Health Survey. J Clin Epidemiol. 1998;51:1139-47 https://doi.org/10.1016/s08954356(98)00105-x

46. Carragher N, Sunderland M, Batterham PJ, Calear AL, Elhai JD, Chapman C, Mills K. Discriminant validity and gender differences in DSM-5 posttraumatic stress disorder symptoms. J Affect Disord. 2016;190:56-67 https://doi.org/10. 1016/j.jad.2015.09.071.

47. Hu L, Bentler PM. Cutoff Criteria for Fit Indexes in Covariance Structure Analysis: Conventional Criteria Versus New Alternatives. Struct Equ Modeling-Multidiscip J. 1999;6:1-55 https://doi.org/10.1080/ 10705519909540118.

48. Raftery AE. Bayesian model selection in social research. Sociol Methodol. 1995:111-63.

49. Lamela D, Soreira C, Matos P, Morais A. Systematic review of the factor structure and measurement invariance of the patient health questionnaire-9 (PHQ-9) and validation of the Portuguese version in community settings. J Affect Disord. 2020;276:220-33 https://doi.org/10.1016/j.jad.2020.06.066.

50. Sun JW, Cao DF, Li JH, Zhang X, Wang Y, Bai HY, et al. Profiles and characteristics of clinical subtypes of perinatal depressive symptoms: A latent class analysis. J Adv Nurs. 2019;75:2753-65 https://doi.org/10.1111/jan. 14136.

51. Rathbun AM, Schuler MS, Stuart EA, Shardell MD, Yau MS, Gallo JJ, et al. Depression Subtypes in Individuals With or at Risk for Symptomatic Knee Osteoarthritis. Arthritis Care Res (Hoboken). 2020;72:669-78 https://doi.org/ 10.1002/acr.23898

52. Thorp JG, Marees AT, Ong J-S, An J, MacGregor S, Derks EM. Genetic heterogeneity in self-reported depressive symptoms identified through genetic analyses of the PHQ-9. Psychol Med. 2019:1-12 https://doi.org/10. 1017/S0033291719002526.

53. Gunzler D, Sehgal AR, Kauffman K, Davey CH, Dolata J, Figueroa M, et al. Identify depressive phenotypes by applying RDOC domains to the PHQ-9. Psychiatry Res. 2020;286:112872 https://doi.org/10.1016/j.psychres.2020. 112872.

54. Papakostas $\mathrm{Gl}$. Cognitive symptoms in patients with major depressive disorder and their implications for clinical practice. J Clin Psychiatry. 2014;75: 8-14 https://doi.org/10.4088/JCP.13r08710.
55. Arnold SRC, Uljarević M, Hwang Y i, Richdale AL, Trollor JN, Lawson LP. Brief Report: Psychometric Properties of the Patient Health Questionaire-9 (PHQ9) in Autistic Adults. J Autism Dev Disord. 2020;50:2217-25 https://doi.org/ 10.1007/s10803-019-03947-9.

56. Patel JS, Oh Y, Rand KL, Wu W, Cyders MA, Kroenke K, Stewart JC. Measurement invariance of the patient health questionnaire-9 (PHQ-9) depression screener in U.S. adults across sex, race/ethnicity, and education level: NHANES 2005-2016. Depress Anxiety. 2019;36:813-23 https://doi.org/ 10.1002/da.22940

57. Elhai JD, Contractor AA, Palmieri PA, Forbes D, Richardson JD. Exploring the relationship between underlying dimensions of posttraumatic stress disorder and depression in a national, trauma-exposed military sample. J Affect Disord. 2011;133:477-80 https://doi.org/10.1016/j.jad.2011.04.035.

58. Sharpley CF, Bitsika V, Christie DRH, Hunter MS. Factor Structure of the Gotland Scale of Male Depression in Two Samples of Men With Prostate Cancer: Implications for Treating Male Depression. Am J Mens Health. 2017; 11:170-5 https://doi.org/10.1177/1557988315599029.

59. Cao C, Wang L, Wu J, Bi Y, Yang H, Fang R, et al. A comparison of ICD- 11 and DSM-5 criteria for PTSD among a representative sample of Chinese earthquake survivors. Eur J Psychotraumatol. 2020;11:1760481 https://doi. org/10.1080/20008198.2020.1760481.

60. Elhai JD, Biehn TL, Armour C, Klopper JJ, Frueh BC, Palmieri PA. Evidence for a unique PTSD construct represented by PTSD's D1-D3 symptoms. J Anxiety Disord. 2011;25:340-5 https://doi.org/10.1016/j.janxdis.2010.10.007.

61. MacKinnon DP. Longitudinal Mediation Models. In: Introduction to statistical mediation analysis; 2008. p. 193-236.

\section{Publisher's Note}

Springer Nature remains neutral with regard to jurisdictional claims in published maps and institutional affiliations.

Ready to submit your research? Choose BMC and benefit from:

- fast, convenient online submission

- thorough peer review by experienced researchers in your field

- rapid publication on acceptance

- support for research data, including large and complex data types

- gold Open Access which fosters wider collaboration and increased citations

- maximum visibility for your research: over $100 \mathrm{M}$ website views per year

At $\mathrm{BMC}$, research is always in progress.

Learn more biomedcentral.com/submissions 